\title{
TESTE RÁPIDO MOLECULAR PARA TUBERCULOSE: CUSTO E CONTRIBUIÇÕES
}

\author{
RAPID MOLECULAR ASSAY FOR \\ TUBERCULOSIS: COST AND CONTRIBUTIONS
}

\section{PRUEBA RÁPIDA MOLECULAR DE LA TUBERCULOSIS: COSTO Y CONTRIBUCIONES}

\author{
Larissa Nicolau Lopes ${ }^{1}$ \\ Lilian Lessa Cardoso ${ }^{2}$ \\ Marcelle Saldanha da Silva ${ }^{3}$ \\ Edvaldo Tonin ${ }^{4}$ \\ Adriana Zilly ${ }^{5}$ \\ Reinaldo Antonio Silva-Sobrinho ${ }^{6}$
}

Como citar este artigo: Lopes LN, Cardoso LL, Silva MS, Tonin E, Zilly A, Silva-Sobrinho RA. Teste rápido molecular para tuberculose: custo e contribuições. Rev baiana enferm. 2020;34:e34803.

Objetivo: identificar o custo da tecnologia Gene Xpert MTB/Rif® e analisar sua contribuição para o diagnóstico rápido da tuberculose. Método: estudo quantitativo e retrospectivo realizado no período de 2014 a 2016. A busca de dados foi realizada no Sistema de Informação de Agravo de Notificação e no Gerenciador de Ambiente Laboratorial. Os dados foram analisados com base nas técnicas de estatística descritiva por meio da distribuição de frequência absoluta e relativa. Resultados: foram estudados 196 casos e a média de tempo para a realização do exame para diagnóstico da tuberculose por meio do Gene Xpert MTB/Rif® foi de dois dias, com custo de R 35,20 por exame realizado. Conclusão: os custos da tecnologia Gene Xpert MTB/Rif ${ }^{\circledR}$ são relativamente superiores ao da baciloscopia de escarro, porém têm-se grandes vantagens quanto ao tempo para a liberação do resultado do exame e maior sensibilidade e especificidade oferecida pelo teste rápido molecular.

Descritores: Tuberculose. Diagnóstico. Tuberculose Pulmonar. Custos e Análise de Custo. Técnicas de Diagnóstico do Sistema Respiratório.

Objective: to identify the cost of the Gene Xpert MTB/Rif® technology and analyze its contribution to the rapid diagnosis of tuberculosis. Method: quantitative and retrospective study, carried out in the period from 2014 to 2016. Data search was performed on the Information System of Disease Notification and on the Laboratory Environment Manager. The data were analyzed based on the techniques of descriptive statistics through distribution of absolute and relative frequency. Results: 196 cases were studied, and the average time to perform the test for diagnosis of tuberculosis through Gene Xpert MTB/Rif® was two days, with a cost of 35.20R\$ per test performed. Conclusion: the

\footnotetext{
Estudante de Enfermagem. Universidade Estadual do Oeste do Paraná. Foz do Iguaçu, Paraná, Brasil. lari.nicolau@hotmail.com. https://orcid.org/0000-0001-63936779.

Enfermeira. Especialista em Unidade de Terapia Intensiva. Docente da Universidade Estadual do Oeste do Paraná. Foz do Iguaçu, Paraná, Brasil. https://orcid. org/0000-0001-9720-1041.

Enfermeira. Universidade Estadual do Oeste do Paraná. Foz do Iguaçu, Paraná, Brasil. https://orcid.org/0000-0002-9407-2659.

4 Farmacêutico. Químico. Universidade Estadual do Oeste do Paraná. Foz do Iguaçu, Paraná, Brasil. https://orcid.org/0000-0003-1210-4379.

5 Bióloga. Doutora em Ciências Biológicas. Docente da Universidade Estadual do Oeste do Paraná. Foz do Iguaçu, Paraná, Brasil. https://orcid.org/0000-0002-87148205.

6 Enfermeiro. Doutor em Enfermagem. Docente da Universidade Estadual do Oeste do Paraná. Foz do Iguaçu, Paraná, Brasil. https://orcid.org/0000-0003-0421-4447.
} 
costs of Gene Technology Xpert MTB/Rif® are relatively higher than that of sputum smear microscopy, but have great advantages in time to release the test result and higher sensitivity and specificity offered by the rapid molecular assay.

Descriptors: Tuberculosis. Finding. Tuberculosis, Pulmonary. Costs and Cost Analysis. Diagnostic Techniques, Respiratory System.

Objetivo: identificar el costo de la tecnología Gene Xpert MTB/Rif® y analizar su contribución para el diagnóstico rápido de la tuberculosis. Método: estudio cuantitativo, retrospectivo, realizado en el periodo de 2014 a 2016. Se realizó la búsqueda de datos en el Sistema de Información de Notificación de Enfermedades y en el Supervisor del Entorno de Laboratorio. Los datos fueron analizados con base en las técnicas de la estadística descriptiva por medio de distribución de frecuencias absolutas y relativas. Resultados: se estudiaron 196 casos y el promedio de tiempo para realizar el examen para el diagnóstico de la tuberculosis por medio del Gene Xpert MTB/Rif® fue de dos dias, con un costo de 35.20R\$ por cada examen realizado. Conclusión: los costos de la tecnología Gene Xpert MTB/Rif® son relativamente más altos que los de la baciloscopia, pero tienen grandes ventajas en el tiempo para la publicación de los resultados del examen y mayor sensibilidad y especificidad ofrecidos por prueba rápida molecular.

Descriptores: Tuberculosis. Hallazgo. Tuberculosis Pulmonar. Costos y Análisis de Costo. Técnicas de Diagnóstico del Sistema Respiratorio.

\section{Introdução}

A saúde pública deve priorizar metas que solucionem os problemas de saúde, para que haja uma melhora na qualidade de vida dos cidadãos. No Brasil, a tuberculose (TB) continua sendo um problema de saúde pública, pois é considerada a $4^{\underline{a}}$ causa de mortes por doenças infecciosas, concentrada em populações vulneráveis como pessoas vivendo com o vírus da imunodeficiência humana/síndrome da imunodeficiência adquirida (HIV/aids), privadas de liberdade, em situação de rua, a população indígena, pessoas que residem em espaços insalubres e em situação de pobreza ${ }^{(1)}$. De acordo com o boletim epidemiológico de 2018, no ano de 2016, ocorreram 4.426 óbitos devido a TB e foram diagnosticadas 69.569 pessoas em 2017, sendo 8.074 notificados na Região Sul, na qual, somente no Paraná identificou-se 1.947 casos novos nesse período ${ }^{(2)}$.

Em 2018, o coeficiente de incidência da TB por grupo de 100.000 habitantes no Brasil foi de 36,58, na Região Sul 29,74, no estado do Paraná 20,03; contudo, em Foz do Iguaçu (PR), o coeficiente de incidência foi superior, sendo mais que o dobro do identificado no Paraná $(47,52)$ (3) Ademais, Foz do Iguaçu é um município peculiar, devido sua localização na fronteira com dois países, Paraguai e Argentina, sendo ainda a segunda cidade do Brasil que mais recebe visita de turistas internacionais, conformando um elevado fluxo de pessoas de diferentes nacionalidades, e, consequentemente, maior oportunidade de transmissão de doenças infectocontagiosas, devido à heterogeneidade e diversidade da população.

Mesmo sendo considerada uma doença endêmica, no território brasileiro há uma preocupação dos profissionais de saúde e dos pesquisadores na área em controlar a transmissão da doença, que ocorre de indivíduo para indivíduo por meio das vias aéreas ${ }^{(4)}$.

A TB pode atingir vários órgãos e sistemas do corpo humano, porém é mais frequente nos pulmões, sendo chamada de TB pulmonar, causada por um bacilo conhecido como Mycobacterium tuberculosis ou Bacilo de Koch, uma bactéria oportunista, que atinge principalmente pessoas com o sistema imunológico vulnerável, como imunodeprimidos e até mesmo aquelas em situações de vulnerabilidade social e sanitária ${ }^{(5)}$. O principal sintoma da TB pulmonar é a tosse por mais de três semanas, que pode ser acompanhada de sudorese noturna, febre, astenia, falta de apetite e, consequentemente, emagrecimento $^{(6)}$.

Importante ressaltar que a $\mathrm{TB}$ tem cura, $\mathrm{O}$ diagnóstico e o tratamento são oferecidos 
gratuitamente pelo Sistema Único de Saúde (SUS). Para o diagnóstico da doença é necessário a realização de exames laboratoriais, como a baciloscopia, considerado um exame de baixo custo. Para realizar a baciloscopia, deve-se coletar o escarro (secreção pulmonar) do paciente e posteriormente a contagem dos bacilos encontrados em uma lâmina com o esfregaço da secreção pulmonar. Esse método de diagnóstico deve ser realizado em duas amostras, isto é, a primeira amostra com o material biológico do paciente, colhido no momento que a pessoa procurou o serviço de saúde e a segunda amostra, com o material biológico colhido no dia seguinte pela $\operatorname{manhã}{ }^{(7)}$.

Atualmente, uma tecnologia denominada Gene Xpert MTB/Rif® pode realizar o teste e apresentar o resultado para o diagnóstico da TB em duas horas, utilizando apenas uma amostra do material biológico e, além disso, verificar se o bacilo é resistente ao antibiótico Rifampicina, principal fármaco utilizado no tratamento ${ }^{(6,8)}$. A plataforma Gene Xpert MTB/Rif ${ }^{\circ}$ é um método rápido, que possibilita que o tratamento seja iniciado o quanto antes, além de potencializar a diminuição do contágio pelo bacilo de $\operatorname{Koch}^{(9)}$.

O Ministério da Saúde (MS), por meio do Programa Nacional de Controle da Tuberculose, iniciou a implantação do Gene Xpert MTB/Rif®, desde 2013, em localidades no Brasil com maior incidência da doença. As dificuldades encontradas na adesão à nova tecnologia foram os laboratórios de saúde pública que não apresentavam estrutura condizente ou pessoal capacitado para essa nova metodologia diagnóstica ${ }^{(9)}$.

A baciloscopia de escarro, em se tratando da TB pulmonar, tem sido custo-efetivo e largamente utilizada nos países em desenvolvimento, como é o caso do Brasil, constituindo-se não somente como forma de diagnóstico, mas também, para medição da carga bacteriana mensal e controle do tratamento ${ }^{(10)}$.

Contudo, frente às necessidades impostas pelo surgimento da TB-multirresistente, a demora no diagnóstico da doença, a alta taxa de morbimortalidade entre os segmentos vulneráveis da população e os fatores que envolvem a garantia do alcance da especificidade e sensibilidade potencial da baciloscopia, novas tecnologias de diagnóstico vem sendo formuladas e implantadas, como é o caso do Gene Xpert MTB/Rif ${ }^{(8-11)}$.

Diante do exposto, esta pesquisa teve como objetivo identificar o custo da tecnologia Gene Xpert MTB/Rif® e analisar a sua contribuição para o diagnóstico rápido da TB em Foz do Iguaçu, Paraná.

\section{Método}

Trata-se de estudo descritivo, retrospectivo, conduzido no contexto de pesquisa operacional. Os dados foram obtidos de fonte secundária, relativo aos casos de TB pulmonar diagnosticados no município de Foz do Iguaçu, Paraná, no período de 2014 a 2016.

A consulta aos dados foi realizada junto ao Serviço de Referência à Tuberculose do município estudado, no Sistema de Informação de Agravos de Notificação (SINAN) e no Gerenciador de Ambiente Laboratorial (GAL).

No período de realização da pesquisa, a rede municipal de saúde estava organizada em cinco distritos sanitários, composto por 30 Unidades de Atenção Primária à Saúde, 2 Unidades de Pronto Atendimento, 1 Serviço de Referência para o Controle da Tuberculose e Hanseníase, 1 ambulatório de Serviço de Atendimento Especializado para atenção em Infecções Sexualmente Transmissíveis (IST)/AIDS, 3 hospitais e 1 Laboratório Municipal de Análises Clínicas. Estes serviços envolvem o diagnóstico, o tratamento/acompanhamento e a vigilância epidemiológica em TB.

A população em estudo foi constituída por doentes com TB pulmonar, diagnosticados com o exame tradicional de baciloscopia de escarro e com o teste molecular rápido - Gene Xpert MTB/Rif® - no período de 2014 a 2016, ambos disponibilizados pelo SUS. Foram excluídos da pesquisa aqueles que constavam os dois meios de diagnóstico na ficha de notificação do SINAN. Durante o período estudado, conforme notificações no SINAN, 320 pessoas tiveram diagnóstico de TB-Pulmonar confirmados pela baciloscopia de escarro e/ou pelo Gene Xpert MTB/Rif®, entretanto, somente 196 pacientes foram 
selecionados para o estudo, devido à falta de informações sobre a data de coleta do escarro ou a data de liberação do resultado dos exames.

Os dados, segundo as variáveis selecionadas, foram digitados em uma planilha de cálculos no Microsoft Excelß e analisados com base em técnicas de estatística descritiva por meio da distribuição de frequência absoluta e relativa.

Para calcular o tempo de obtenção do resultado do exame para confirmar ou descartar a TB, utilizando o Gene Xpert MTB/Rif®, foi necessário calcular a média aritmética de dias, a partir da data da coleta do escarro até a liberação do resultado do exame, conforme registrado no GAL.

No entanto, para encontrar a média do tempo (dias) de obtenção do resultado do exame pela técnica da baciloscopia de escarro, foi necessário recorrer ao Manual Nacional de Vigilância Laboratorial da Tuberculose e outras Micobactérias do Ministério da Saúde ${ }^{(12)}$, que indica o tempo máximo para emissão do resultado, $24 \mathrm{~h}$ - um dia (T), considerando também a viabilidade da amostra (VA) que é de cinco a sete dias, visto que a data da coleta do escarro para a realização do exame não estavam disponíveis no GAL e nem de modo completo no SINAN. Assim, utilizou-se a fórmula representada a seguir: $\mathrm{VA}+\mathrm{T}$ $=\mathrm{X}(7$ dias +1 dia $=8$ dias $)$, aplicando o cálculo de média aritmética, na qual, a soma de todos os valores é dividida pelo número de elementos somados para encontrar em quantos dias (média) o resultado da baciloscopia é liberado .

$$
\begin{gathered}
\text { Média aritmética: } \overline{\mathrm{X}} \\
\text { Número de elementos: } \mathrm{n} \\
\overline{\mathrm{X}}=\frac{\left(\mathrm{X}_{1}+\mathrm{X}_{2}+\mathrm{X}_{3}+\ldots+\mathrm{X}_{\mathrm{n}}\right)}{\mathrm{n}} \\
\text { Após o conhecimento da média de tempo } \\
\text { (dias) que o doente esperou para obter o resul- } \\
\text { tado do exame pela técnica de baciloscopia de } \\
\text { escarro e pelo teste molecular rápido Gene Xpert } \\
\text { MTB/Rif®, foi calculado, por meio da equação }
\end{gathered}
$$

a seguir, a quantidade de pessoas que o doente potencialmente poderia infectar durante a espera da confirmação do resultado positivo de TB em um ano. Considerando informações do Ministério da Saúde ${ }^{(10)}$, que sinaliza que um doente com TB pulmonar pode transmitir a doença e infectar de 10 a 15 pessoas durante um ano, os pesquisadores optaram em assumir o valor máximo (15 pessoas/ano).

$$
\begin{aligned}
& \mathrm{X}=\frac{\text { Total de dias do ano }}{\text { Quantidade de pessoas que um }} \\
& \text { doente pode infectar ao ano }
\end{aligned}
$$

Portanto, para calcular a quantidade de pessoas que poderia potencialmente se infectar com o Mycobacterium tuberculosis durante a espera da confirmação do resultado do exame, caso ele fosse positivo, aplicou-se a equação $X=y \cdot z$ (sendo $y$ a quantidade de pessoas que podem se infectar, e $z$, o número de dias esperado para receber o resultado do diagnóstico de $\mathrm{TB}$ ).

Quanto ao custo do teste molecular Gene Xpert MTB/Rif ${ }^{\circledR}$ e da baciloscopia de escarro, a referência para o levantamento dos valores monetários foi o Relatório Técnico: Estudos econômicos da incorporação do teste molecular Gene Xpert MTB/Rif® para o diagnóstico de tuberculose pulmonar no Sistema Único de Saúde ${ }^{(13)}$.

O estudo foi aprovado pelo Comitê de Ética em Pesquisa (CEP) Envolvendo Seres Humanos, com Parecer n. 2.515.366.

\section{Resultados}

A população masculina representou 74,5\% dos indivíduos acometidos com TB-pulmonar, a faixa etária de maior frequência foi a de 20-39 anos, a etnia branca teve representatividade de $60,2 \%$, e em relação à escolaridade, a maioria informou ter cursado o ensino fundamental incompleto $(57,1 \%)$ (Tabela 1$)$. 
Tabela 1 - Distribuição das variáveis sociodemográficas de pessoas diagnosticadas com tuberculose. Foz do Iguaçu, Paraná, Brasil - 2014-2016 (N=196)

\begin{tabular}{|c|c|c|}
\hline Características & $\mathbf{n}$ & $\%$ \\
\hline \multicolumn{3}{|l|}{ Sexo } \\
\hline Masculino & 146 & 74,5 \\
\hline Feminino & 50 & 25,5 \\
\hline \multicolumn{3}{|l|}{ Faixa Etária } \\
\hline 01 a 19 & 18 & 9,2 \\
\hline 20 a 39 & 95 & 48,5 \\
\hline 40 a 59 & 67 & 34,2 \\
\hline 60 a 79 & 13 & 6,6 \\
\hline 80 a 99 & 3 & 1,5 \\
\hline \multicolumn{3}{|l|}{ Etnia } \\
\hline Branca & 118 & 60,2 \\
\hline Preta & 10 & 51 \\
\hline Amarela & 2 & 1,0 \\
\hline Parda & 64 & 32,7 \\
\hline Indígena & 0 & 0,0 \\
\hline Ignorado & 2 & 1,0 \\
\hline \multicolumn{3}{|l|}{ Escolaridade } \\
\hline Analfabeto & 8 & 4,1 \\
\hline Ensino Fundamental Incompleto & 112 & 57,1 \\
\hline Ensino Fundamental Completo & 17 & 8,7 \\
\hline Ensino Médio Incompleto & 18 & 9,2 \\
\hline Ensino Médio Completo & 16 & 8,2 \\
\hline Educação Superior Incompleta & 4 & 2,0 \\
\hline Educação Superior Completa & 1 & 0,5 \\
\hline Ignorado/Não se aplica/Inconclusivo & 20 & 10,2 \\
\hline
\end{tabular}

Fonte: Elaboração própria.

Na Tabela 2, observa-se que no ano de 2014, 64,8\% dos pacientes obtiveram diagnóstico de TB por meio da baciloscopia de escarro, sendo as Unidades Básicas de Saúde (UBS) as principais fontes de notificação neste período (68\%). Quanto à busca ativa de casos entre os contatos de doentes de TB examinados, registrou-se que $85 \%$ foram avaliados. A média de tempo para a realização do exame para diagnóstico foi de dois dias, quando utilizado o teste molecular rápido Gene Xpert MTB/Rif®, a um custo de R\$ 35,20 por exame realizado.

Tabela 2 - Dados operacionais dos pacientes diagnosticados e notificados com tuberculose. Foz do Iguaçu, Paraná, Brasil - 2014-2016

\begin{tabular}{l|c|c|c|c}
\hline Variáveis & Frequência & $\mathbf{0}$ & $\begin{array}{c}\text { Média } \\
\text { (dias) }\end{array}$ & $\begin{array}{c}\text { Valor monetário } \\
\text { (R\$) }\end{array}$ \\
\hline Tipo e ano de Diagnóstico & & & & - \\
$\quad$ Baciloscopia de Escarro 2014 & 127 & 64,8 & - & - \\
Gene Xpert MTB/Rif® 2015 & 39 & 19,9 & - & - \\
Gene Xpert MTB/Rif® 2016 & 30 & 15,3 & - & - \\
Total & 196 & 100 & - & - \\
Instituição Notificadora & & & & - \\
Unidade Básica de Saúde & 134 & 68,0 & - & - \\
Pronto Atendimento & 20 & 10,2 & - & - \\
Hospital & 39 & 19,8 & - & - \\
Centro de Especialidades Médicas & 3 & 2,0 & - &
\end{tabular}


Tabela 2 - Dados operacionais dos pacientes diagnosticados e notificados com tuberculose. Foz do Iguaçu, Paraná, Brasil - 2014-2016

(conclusão)

\begin{tabular}{|c|c|c|c|c|}
\hline Variáveis & Frequência & $\%$ & $\begin{array}{l}\text { Média } \\
\text { (dias) }\end{array}$ & $\begin{array}{c}\text { Valor monetário } \\
(\mathrm{R} \$)\end{array}$ \\
\hline \multicolumn{5}{|l|}{ Contatos dos pacientes } \\
\hline Contatos identificados & 523 & 100 & - & - \\
\hline Contatos examinados & 443 & 85 & - & - \\
\hline \multicolumn{5}{|c|}{ Média do tempo de espera do Resultado } \\
\hline Baciloscopia de Escarro & - & - & $4,5^{\mathrm{a}}$ & - \\
\hline Gene Xpert MTB/Rif® & - & - & 2 & - \\
\hline \multicolumn{5}{|c|}{ Custo Unitário dos diagnósticos ${ }^{\mathrm{b}}$} \\
\hline Baciloscopia de Escarro & - & - & - & 14,40 \\
\hline Gene Xpert MTB/Rif® & - & - & - & 35,20 \\
\hline
\end{tabular}

Fonte: Elaboração própria.

Nota: Sinal convencional utilizado:

- Dado numérico igual a zero não resultante de arredondamento.

a A média do tempo de espera do resultado da baciloscopia foi estabelecida com base nos dados do Manual Nacional de Vigilância Laboratorial da Tuberculose e outras Micobactérias do Ministério da Saúde ${ }^{(12)}$.

${ }^{\mathrm{b}}$ Com base no Relatório Técnico: Estudos econômicos da incorporação do teste molecular Gene Xpert MTB/Rifß para o diagnóstico de tuberculose pulmonar no Sistema Único de Saúde ${ }^{(13)}$.

A quantidade de pessoas que poderia potencialmente se infectar com o Mycobacterium tuberculosis durante a espera da confirmação do resultado positivo de TB, junto a um caso suspeito, é de 0,08 pessoas quando o teste empregado é o exame Gene Xpert MTB/Rif® e 0,18 pessoas quando o método é a baciloscopia de escarro.

\section{Discussão}

O conhecimento da população que apresenta maior probabilidade de desenvolver a doença permite o direcionamento de métodos de prevenção e cuidados à população de maior risco. O perfil sociodemográfico dos pacientes de Foz do Iguaçu é semelhante a algumas regiões do país, como no estado do Rio de Janeiro ${ }^{(14)}$ e no Vale do Ribeira ${ }^{(15)}$.

Presume-se que a justificativa esteja ligada à vulnerabilidade dos indivíduos independentemente da localização geográfica, uma vez que, mesmo em localidades com alto perfil de renda e Índice de Desenvolvimento Humano (IDH) existirão grupos em vulnerabilidade, visto que uma das causas globais da persistência da ocorrência da TB é a desigualdade social, que provoca assimetria no acesso à renda, aparatos educacionais, moradia/gregária, segurança e alcance de qualidade de vida ${ }^{(16)}$.

Um dos artifícios para se diagnosticar essa doença é a baciloscopia de escarro, um método rápido, simples e de baixo custo para o SUS. Outro método mais rápido é o Gene Xpert MTB/Rif ${ }^{\circledR}$ que, em cerca de duas horas, pode apontar o resultado e, além do diagnóstico, identifica se há resistência à Rifampicina, um dos antibióticos utilizados no tratamento ${ }^{(17)}$.

A Organização Mundial da Saúde historicamente enfatiza a importância de pesquisar estratégias que fortaleçam o acesso à prevenção, ao diagnóstico e ao tratamento da TB, com a finalidade de diminuir a incidência e a mortalidade pela doença ${ }^{(16)}$. Assim, o Plano Nacional pelo Fim da Tuberculose contempla medidas nessa direção, de modo que, no ano de 2013, o Teste Rápido Molecular para Tuberculose (TRM-TB) foi incluído no SUS, conformado por uma Rede de Teste Rápido para TB, formada por 127 laboratórios de 92 municípios. Foz do Iguaçu está incluída, por se enquadrar nos critérios de eleição, sendo um deles, ser município de fronteira internacional ${ }^{(18)}$.

Desde então, o município de Foz do Iguaçu vem implementando o diagnóstico de casos 
novos por meio do TRM-TB. Destaca-se que a frequência de casos diagnosticados com esse método é maior, mas devido à falta de informação sobre a data de entrada do pedido no sistema e a liberação do resultado, não puderam ser considerados nesta pesquisa.

Um importante caminho para diagnosticar os casos sintomáticos de TB pulmonar na comunidade deve ocorrer junto ao trabalho dos Agentes Comunitários de Saúde (ACS), que possuem vínculo com as famílias e interagem no espaço (moradias) onde vivem as pessoas. Assim, o ACS junto com a sua equipe, vinculada a uma UBS, tem papel principal na descoberta de casos novos ${ }^{(19)}$.

Neste estudo, 32\% dos casos novos foram diagnosticados fora das UBS, mesmo o controle da TB estando formalmente descentralizado para a Atenção Primária à Saúde. Um estudo realizado em Manaus mostrou que 0,20\% dos casos foram notificados em instituições hospitalares ${ }^{(20)}$. Esses números são importantes, pois a existência de notificações de TB no ambiente hospitalar indica que houve diagnóstico tardio e situação de urgência/emergência frente à saúde do paciente, isto é, o tempo para procurar o sistema de saúde foi mais longo e/ou a equipe da UBS não conseguiu realizar busca ativa necessária para alcançar os indivíduos ${ }^{(19)}$.

Outro ponto indispensável de ser discutido é a quantidade de contatos de doente de TB examinados. Essa é uma atividade que precisa ser realizada pelas UBS, vital para o diagnóstico de casos novos e fundamental para diminuir a prevalência da doença. Nesta pesquisa foi evidenciado que 85\% dos contatos dos doentes foram examinados, um resultado positivo quando comparado ao percentual das capitais brasileiras em 2017, em que o melhor percentual foi nas cidades de São Luís (MA) $(77,5 \%)$ e em Brasília (DF) $(66,3 \%)^{(2)}$.

Em se tratando da média do tempo de espera do resultado dos exames diagnósticos para TB, quando a técnica aplicada foi a baciloscopia, foi preciso 4,5 dias, em média, para a emissão do resultado, embora de acordo com o Manual de Recomendações para o Controle da Tuberculose no Brasil o resultado da baciloscopia deve estar disponível em até $24 \mathrm{~h}^{(10-12)}$. Como constatado, isso não ocorreu neste estudo, e pode ter sido desencadeado por vários motivos, como por exemplo, o número elevado de exames a serem realizados pelo laboratório, a gestão para encaminhar a amostra do material biológico, e também a logística do retorno para o resultado ser emitido ao paciente. Esses desafios podem aumentar a média de tempo para obter-se o diagnóstico. O Gene Xpert MTB/Rif® pode detectar a bactéria na amostra em apenas 2 horas ${ }^{(18)}$, porém, por questões relacionadas à gestão, o resultado em Foz do Iguaçu levou, em média, dois dias para ser disponibilizado. Dessa forma, o Gene Xpert MTB/Rif ${ }^{\circledR}$, apesar de ser um método rápido, devido a questões relacionadas à logística de transporte de amostras e disponibilização do resultado, pode elevar e postergar o diagnóstico com confirmação laboratorial.

Sabendo que um indivíduo com TB pulmonar pode transmitir o bacilo para até 15 pessoas em um ano ${ }^{(10)}$, o período de espera do diagnóstico pode aumentar ou diminuir a incidência de transmissão, dependendo do método utilizado para identificar a bactéria.

Sob essa perspectiva, de acordo com o tempo de emissão do resultado (conforme mostrado neste estudo), o doente poderá infectar 0,08 pessoas (em 2 dias) quando a técnica de identificação do Mycobacterium tuberculosis é o Gene Xpert MTB/Rif®; por outro lado, quando a identificação é feita pela baciloscopia de escarro, o valor sobe para 0,18 pessoas (4,5 dias). Esses valores quando observados de forma isolada são pequenos, porém apresentam ampla disseminação ao se analisar com os valores de casos novos no país. Diante disso, defende-se que a necessidade de apenas uma amostra de escarro e a automação implicada no Gene Xpert MTB/Rif ${ }^{\circledR}$ foi a principal variável que acelerou a disponibilização do resultado do exame, diminuindo a oportunidade de propagação da doença.

Outro aspecto considerável é o custo da baciloscopia (R\$ 14,40) e do Gene Xpert MTB/Rif ${ }^{\circledR}$ (R\$ 35,20). No entanto, a baciloscopia deve ser realizada em duas amostras, isto é, duas vezes ${ }^{(7)}$; dessa maneira, o valor final do exame, quando realizado com baciloscopia, é de $\mathrm{R} \$ 28,80$. 
Diante desses resultados, pode-se dizer que o custo da baciloscopia continua sendo inferior ao Gene Xpert MTB/Rif®, com diferença de R\$ 6,40. Porém, estudo ${ }^{(21)}$ afirma que a baciloscopia deve atingir $70 \%$ de sensibilidade, e realizando as duas baciloscopias recomendadas pode chegar a $80 \%$. Por outro lado, a nova tecnologia possui maior sensibilidade (88\%) para identificar o bacilo causador da TB, o que consequentemente diminui as chances de erro do resultado. Destaca-se que gestantes e pacientes imunodeprimidos, como portadores de HIV, apresentam maior dificuldade em diagnosticar a doença, porém, de acordo com estudos, o Gene Xpert MTB/Rif®, ainda assim, possui maior sensibilidade ${ }^{(22)}$.

Conforme publicação no Boletim Brasileiro de Avaliação de Tecnologias em Saúde (BRATS), a sensibilidade de testes em amostras com resultados positivos para baciloscopia e para cultura em estudo é de $98 \%$ a 100\%, porém o teste foi capaz de detectar até $78 \%$ dos casos negativos à baciloscopia (falso-negativo com baciloscopia). Caso haja resultados de falso-negativo em baciloscopia, esse número pode aumentar progressivamente, o que seria evitado pela utilização do teste molecular. Quanto à especificidade, os resultados obtidos com o Gene Xpert MTB/Rif® variam de 90,9\% a 100\%, em relação à cultura ${ }^{(17)}$.

Dessa maneira, mesmo sendo $\mathrm{R} \$$ 6,40 mais caro, o Gene Xpert MTB/Rif® tem vantagens em relação à rapidez e à especificidade na obtenção do resultado, e adicionalmente detecta a presença de resistência à rifampicina, informação que proporciona o estabelecimento do esquema de tratamento adequado ao paciente. Assim, quanto mais rápido for o diagnóstico da TB, mais rápida também pode ser a cura, e menor é o risco de disseminação da doença ${ }^{(23)}$.

As limitações desta pesquisa estão ligadas àquelas inerentes ao uso de dados de base secundária. A influência direta disso nos resultados do estudo foi a falta de dados para identificar o tempo demandado para análise e liberação do resultado do exame, quando utilizado a técnica de diagnóstico de baciloscopia de escarro.

\section{Conclusão}

O diagnóstico rápido é uma das soluções para a diminuição dos índices de TB, visto que após o resultado do exame e o tratamento, interrompe-se a cadeia de transmissão do bacilo causador da doença. A nova tecnologia de diagnóstico apresenta um custo maior, por ser um equipamento de alta tecnologia, porém seus benefícios garantem precisão, segurança e rapidez no diagnóstico, o que pode trazer grandes transformações na assistência em TB. Entretanto, para que isso ocorra, o Gene Xpert MTB/Rif ${ }^{\circledR}$ deve ser disponibilizado para os municípios juntamente com capacitações para os profissionais da área da saúde, possibilitando a mudança operacional com impacto na saúde da coletividade.

Além do aspecto econômico, vale ser considerada a importância dos casos falso-negativos sobre os testes de baciloscopia para a Mycobacterium tuberculosis, pois, com a tecnologia do Gene Xpert MTB/Rif® esse problema é drasticamente reduzido. Na ocorrência de umfalso-negativo, o paciente contaminado torna-se fonte de transmissão à população, disseminando a doença, até que seja futuramente diagnosticado e tratado, sendo este aspecto uma séria questão a ser resolvido pela saúde pública. O diagnóstico rápido para $\mathrm{TB}$ colabora na diminuição da transmissão da doença e, em longo prazo, diminui a prevalência e, por conseguinte, a diminuição dos custos, pois havendo menos pessoas infectadas, haverá menos pessoas precisando de diagnósticos e tratamento.

Espera-se que futuros estudos sejam realizados sobre a utilização de novas tecnologias na detecção e tratamento da TB, contribuindo com a discussão sobre custo/efetividade, tendo como norte o controle da doença.

\section{Colaborações:}

1 - concepção, projeto, análise e interpretação dos dados: Larissa Nicolau Lopes e Reinaldo Antonio Silva-Sobrinho; 
2 - redação do artigo e revisão crítica relevante do conteúdo intelectual: Larissa Nicolau Lopes, Lilian Lessa Cardoso, Marcelle Saldanha da Silva, Edvaldo Tonin, Adriana Zilly e Reinaldo Antonio Silva-Sobrinho;

3 - aprovação final da versão a ser publicada: Larissa Nicolau Lopes e Reinaldo Antonio Silva-Sobrinho.

\section{Referências}

1. Brasil. Ministério da Saúde. Secretaria de Vigilância em Saúde. Programa Nacional de Controle da Tuberculose [Internet]. Brasília (DF); 2018 [cited 2019 Oct 28]. Available from: https:// portalarquivos2.saude.gov.br/images/pdf/2018/ marco/19/APRES-PADRAO-JAN-2018-REDUZIDA.pdf

2. Brasil. Ministério da Saúde. Implantação do Plano Nacional pelo Fim da Tuberculose como Problema de Saúde Pública no Brasil: primeiros passos rumo ao alcance das metas. Boletim Epidemiológico [Internet]. 2018 [cited 2019 Nov 5];49(11):1-18. Available from: https://www.saude.gov.br/images/ pdf/2018/marco/26/2018-009.pdf

3. Brasil. Ministério da Saúde. Informacões de saúde. Epidemiológicas e Morbidade (Tabwin) Brasília (DF); 2019 [cited 2020 Mar 18]. Available from: http://tabnet.datasus.gov.br/cgi/tabcgi.exe? sinannet/cnv/tubercpr.def

4. Pedro HSP, Nardi SMT, Finardi AJ, Moraes EB, Oliveira RS, Pereira MIF, et al. Cenário atual da tuberculose. Hansen Int [Internet]. 2014 [cited 2019 Oct 30];39(1):40-55. Available from: http://www.ilsl.br/revista/detalhe_artigo. php?id=12229

5. Azevedo JAM, David LSMH, Marteleto MR. Redes sociais de usuários portadores de tuberculose: a influência das relações no enfrentamento da doença. Saúde debate. 2018 jun; 42(117):442-54. DOI: https://doi.org/10.1590/0103-1104201811708

6. Kozakevich GV, Silva RM. Tuberculose: revisão de literatura. Arq Catarin Med [Internet]. 2015 [cited 2019 Nov 5];44(4):34-47. Available from: http:// www.acm.org.br/acm/seer/index.php/arquivos/ article/view/46/42

7. Brasil. Ministério da Saúde. Secretaria de Vigilância em Saúde. Departamento de Vigilância Epidemiológica. Guia de Vigilância em Saúde [Internet]. Brasília (DF); 2019 [cited 2019 Nov 3].
Available from: http://bvsms.saude.gov.br/bvs/ publicacoes/guia_vigilancia_saude_3ed.pdf

8. Casela M, Cerqueira SMA, Casela TO, Pereira MA, Santos SQ, Pozo FAD, et al. Rapid molecular test for tuberculosis: impact of its routine use at a referral hospital. J bras pneumol. 2018 Apr;44(2):112-7. DOI: http://dx.doi.org/10.1590/ s1806-37562017000000201

9. Pinto MFT, Steffen R, Entringer A, Costa ACC, Trajman A. Impacto orçamentário da incorporação do GeneXpert MTB/RIF para o diagnóstico da tuberculose pulmonar na perspectiva do Sistema Único de Saúde, Brasil, 2013-2017. Cad Saúde Pública. 2017;33(9):e00214515. DOI: http:// dx.doi.org/10.1590/0102-311x00214515

10. Brasil. Ministério da Saúde. Secretaria de Vigilância em Saúde. Departamento de Vigilância das Doenças Transmissíveis. Manual de Recomendações para o Controle da Tuberculose no Brasil [Internet]. Brasília (DF); 2019 [cited 2019 Nov 3]. Available from: http://bvsms.saude.gov.br/bvs/ publicacoes/manual_recomendacoes_controle_ tuberculose_brasil_2_ed.pdf

11. Steingart KR, Schiller I, Horne DJ, Pai M, Boehme CC, Dendukuri N. Xpert ${ }^{\circledR}$ MTB/RIF assay for pulmonary tuberculosis and rifampicin resistance in adults. Cochrane Database Syst Rev. 2014;(1):CD009593. DOI: 10.1002/14651858. CD009593.pub3

12. Brasil. Ministério da Saúde. Secretaria de Vigilância em Saúde. Departamento de Vigilância Epidemiológica. Manual Nacional de Vigilância Laboratorial da Tuberculose e outras Micobactérias [Internet]. Brasília (DF); 2008 [cited 2019 Nov 3] Available from: http://bvsms.saude.gov.br/bvs/ publicacoes/manual_vigilancia_laboratorial_ tuberculose.pdf

13. Brasil. Ministério da Saúde. Secretaria de Vigilância em Saúde. Programa Nacional de Controle da Tuberculose. Relatório técnico. Estudos econômicos da incorporação do teste molecular GeneXpert $^{\mathrm{TM}}$ MTB/Rif para o diagnóstico de tuberculose pulmonar no Sistema Único de Saúde. Brasília; 2013 [cited 2019 Nov 4]. Available from: http://www.fundacaoataulphodepaiva.com. br/2013/07/Relatorio-tecnico_25042013.pdf

14. Santos NJ, Sales MMC, Prado NT, Maciel LE. Fatores associados à cura no tratamento da tuberculose no estado do Rio de Janeiro, 2011-2014. Epidemiol Serv Saúde. 2018;27(3):e2017464. DOI: https://doi. org/10.5123/S1679-49742018000300015 
15. Pereira TLV, Pereira TI, Elias GP, Medeiro MCP, Souza AL. A Incidência de Tuberculose no Vale do Ribeira. Rev Gestão em Foco [Internet]. 2017 [cited 2019 Nov 4];9:90-102. Available from: http://portal. unisepe.com.br/unifia/wp-content/uploads/ sites/10001/2018/06/011_incidencia_tuberculose. pdf

16. World Health Organization. Global tuberculosis control: surveillance, planning financing [Internet]. Geneva; 2006 [cited 2019 Nov 4]. Available from: https://apps.who.int/s///10665/144567/924156314 1_f;jsessionid=B511E0D4213E200D68D69971F5C1 $37 \mathrm{CC}$ ?sequence $=1$

17. Brasil. Ministério da Saúde. Agência Nacional de Vigilância Sanitária. XPER ${ }^{\circledR}$ MTB/RIF no diagnóstico da tuberculose pulmonar. Boletim Brasileiro de Avaliação de Tecnologias em Saúde [Internet]. 2011 set [cited 2019 Nov 5];6(16). Available from: http://bvsms.saude.gov.br/bvs/ periodicos/brats_16.pdf

18. Lima MT, Belotti UCN, Nardi TMS, Pedro PSH. Teste rápido molecular GeneXpert MTB/RIF para diagnóstico da tuberculose. Rev Pan-Amaz Saude. 2017;8(2):65-76. DOI: http://dx.doi.org/10.5123/ s2176-62232017000200008

19. Gaspar LMS. Conhecimento, atitudes e práticas dos agentes comunitários de saúde sobre tuberculose pulmonar no Município do Recife [dissertação] Recife (PE): Fundação Oswaldo Cruz; 2016 [cited 2019 Nov 5]. Available from: https://www.arca. fiocruz.br/handle/icict/22915
20. Farias SA. Perfil dos doentes de tuberculose no município de Manaus - Amazonas (2007) [dissertação]. São Paulo (SP): Universidade de São Paulo; 2010 [cited 2019 Nov 2]. Available from: https://teses.usp.br/teses/disponiveis/22/ $22133 / \mathrm{tde}-14012011-155730 / \mathrm{publico} /$ ALTAIRSEABRADEFARIAS.pdf

21. Pinto M, Entringer PA, Steffen R, Trajman A. Análise de custos de um teste de amplificação de ácido nucleico para o diagnóstico da tuberculose pulmonar sob a perspectiva do Sistema Único de Saúde. J bras pneumol. 2015;41(6):536-8. DOI: https://doi.org/10.1590/s1806-37562015000004524

22. Habib GZ, Dayyab MF, Sanda A, Tambuwal HS, Dalhat MM, Muhammad $\mathrm{H}$, et al. Role of GeneXpert MTB/Rif Assay in Diagnosing Tuberculosis in Pregnancy and Puerperium. Case Rep Infect Dis. 2015(794109):1-5. DOI: 10. $1155 / 2015 / 794109$

23. Savioli MTG, Morrone N, Santoro I. Primary bacillary resistance in multidrug-resistant tuberculosis and predictive factors associated with cure at a referral center in São Paulo, Brazil. J Bras Pneumol. 2019;45(2):e20180075. DOI: 10.1590/1806-3713/ e20180075

Recebido: 9 de dezembro de 2019

Aprovado: 25 de março de 2020

Publicado: 6 de maio de 2020

A Revista Baiana de Enfermagem utiliza a Licença Creative Commons - Atribuição-NãoComercial 4.0 Internacional. https://creativecommons.org/licenses/by-nc/4.0/ Este artigo é de acesso aberto distribuído sob os termos da Licença Creative Commons (CC BY-NC). Esta licença permite que outros remixem, adaptem e criem a partir do seu trabalho para fins não comerciais. Embora os novos trabalhos tenham de lhe atribuir o devido crédito e não possam ser usados para fins comerciais, os usuários não têm de licenciar esses trabalhos derivados sob os mesmos termos. 